Tropical Journal of Pharmaceutical Research January 2017; 16 (1): 149-154

ISSN: $1596-5996$ (print); 1596-9827 (electronic)

(c) Pharmacotherapy Group, Faculty of Pharmacy, University of Benin, Benin City, 300001 Nigeria.

All rights reserved.

Available online at http://www.tjpr.org

Original Research Article

http://dx.doi.org/10.4314/tjpr.v16i1.19

\title{
Molecular identification of TEM-116 beta-lactamase gene in isolates of pathogenic Pseudomonas aeruginosa: A first report from Pakistan
}

\author{
Waheed Ullah ${ }^{1,2}$, Muhammad Qasim², Hazir Rahman ${ }^{2}$, Fazli Bari ${ }^{3}$, Saadullah \\ Khan ${ }^{1}$, Tamara Dworeck ${ }^{4}$ and Noor Muhammad ${ }^{1 *}$ \\ ${ }^{1}$ Department of Biotechnology and Genetic Engineering, ${ }^{2}$ Department of Microbiology, Kohat University of Science \& \\ Technology, Kohat, ${ }^{3}$ Department of Microbiology, Lady Reading Hospital, Peshawar, Pakistan. ${ }^{4}$ Department of Microbiology, \\ RWTH, Aachen University, Aachen, Germany
}

*For correspondence: Email: noormwazir@yahoo.com,dr.noor@kust.edu.pk; Tel: +923028081457

\begin{abstract}
Purpose: Purpose: To determine TEM-116 beta-lactamase gene prevalence in drug-resistant Pseudomonas aeruginosa isolates from Pakistan.

Methods: Sequence analysis of TEM beta-lactamase isolates and their antibiotic susceptibility patterns were carried out. Quantitative bacteriostatic concentrations for commonly used antibiotics were measured against TEM-116 beta-lactamase isolates.

Results: Among the 102 isolates of P. aeruginosa, 23 (22.5\%) were TEM beta-lactamase producers. Sequence analysis of TEM gene from selected isolates showed homology with TEM-116. Two mutations at positions 84 (p.Val84lle) and 184 (p.Ala184Val) were documented. The TEM-116 isolates exhibited $100 \%$ resistance to sulphamethoxazole/trimethoprim, amoxycillin/clavulanic acid and doxycycline, but showed sensitivity to levofloxacin, norfloxacin and amikacin. One TEM-116 P. aeruginosa (PA11) isolate was resistant to all available antibiotics.

Conclusion: These results reveal increased antibiotic resistance in the TEM-116 P. aeruginosa isolates studied, a phenomenon which will be helpful in understanding the molecular mechanisms of antibiotic resistance in $P$. aeruginosa.
\end{abstract}

Keywords: P. aeruginosa, Clinical isolates, Sequencing, TEM-116, Antibiotic susceptibility

Tropical Journal of Pharmaceutical Research is indexed by Science Citation Index (SciSearch), Scopus, International Pharmaceutical Abstract, Chemical Abstracts, Embase, Index Copernicus, EBSCO, African Index Medicus, JournalSeek, Journal Citation Reports/Science Edition, Directory of Open Access Journals (DOAJ), African Journal Online, Bioline International, Open-J-Gate and Pharmacy Abstracts

\section{INTRODUCTION}

$P$. aeruginosa is the leading cause of nosocomial infections in immuno-compromised patients in hospitals. The frequency of $P$. aeruginosa infections is high in burn patients due to easier access of pathogens [1]. Emergence of antibiotics resistance in $P$. aeruginosa is a major public health concern because the resistant organisms produce a wide range of beta lactamases. Production of extended spectrum beta lactamases (ESBLs) is the principle mechanism involved in coping with antibiotics by $P$. aeruginosa [2]. The recent increase in ESBLs production by $P$. aeruginosa is alarming in developing countries due to non-judicious use/abuse of antibiotics. This practice engenders new modes of resistance while augmenting the prevalence of drug-resistant bacteria [3-5]. Among the ESBLs, TEM-1 beta-lactamase was first identified in $E$. coli and later-on in $P$. aeruginosa $[6,7]$. TEM-1 is the most commonly encountered beta-lactamase in Gram-negative bacteria. Up to $90 \%$ of ampicillin resistance in $E$. 
coli is due to the production of beta-lactamase by TEM-1 gene. TEM-2, the first derivative of TEM1 , has a single amino acid substitution from the original beta-lactamase $[8,9]$. Characterization of beta-lactamases in drug-resistant $P$. aeruginosa will be crucial in the study of mechanisms of molecular pathogenesis and virulence.

The present study was undertaken to screen and identify TEM beta lactamases among clinical isolates of $P$. aeruginosa in Pakistan. Moreover, antibiotic susceptibility was performed in TEM producing isolates.

\section{EXPERIMENTAL}

The study was conducted at the Department of Biotechnology and Genetic Engineering, Kohat University of Science and Technology, Kohat, Pakistan. Samples totalling 102 were collected from a tertiary care hospital, Peshawar, Khyber Pakhtunkhwa, Pakistan and aseptically transported to the research laboratory.

\section{Pure culture of $P$. aeruginosa isolates}

In our previous study, a total of 102 isolates were identified as $P$. aeruginosa on the basis of phenotypic and species specific PCR [10]. Pure cultures of $P$. aeruginosa were processed for this study. All the isolates were re-confirmed by biochemical assays using standard protocols.

\section{Molecular detection of TEM beta-lactamase in $P$. aeruginosa}

TEM gene amplification was checked in all 102 isolates of $P$. aeruginosa. Primers used were as follows: TEM forward 5'-TCGGGGAAATGTGCG3 ' and TEM reverse 5'-TGCTTAATCAGTGA GGCACC-3'primers [8]. Ready PCR mixture contained $10 \mathrm{mM}$ Tris $\mathrm{HCl}, 50 \mathrm{mM} \mathrm{KCl}, 1.5 \mathrm{mM}$ $\mathrm{MgCl}_{2}, 0.5 \mathrm{mM}$ DDT, glycerol, Gelatin, NP-40, $0.05 \mathrm{mM}$ Tween-20, $0.2 \mathrm{mM}$ dNTPs and Taq DNA polymerase. $1 \mu \mathrm{L}$ genomic DNA was used for every reaction in a total volume of $25 \mu \mathrm{L}$. The following PCR conditions were used for TEM gene amplification of $P$. aeruginosa: initial denaturation at $95{ }^{\circ} \mathrm{C}$ for $5 \mathrm{~min}$ followed by 35 cycles, $94{ }^{\circ} \mathrm{C}$ for $1 \mathrm{~min}, 58{ }^{\circ} \mathrm{C}$ for $1 \mathrm{~min}, 72{ }^{\circ} \mathrm{C}$ for $1 \mathrm{~min}$ and final extension for $7 \mathrm{~min}$. The amplified product was separated on agarose gel and visualized under UV trans-illuminator.

\section{Sequencing of amplified TEM gene and bioinformatics analysis}

Amplified PCR product was sequenced using forward primer for the TEM gene. Sequencing reactions were performed by Macrogen (Seoul) Korea. Online available Bioedit software was used for sequence analysis. Amino acid sequence of TEM was analysed on translation tool (www.expasy.org/) and was matched with all previously reported TEM genes [11].

Antibiotic susceptibility assay of TEM-116 beta-lacatamase-producing $P$. aeruginosa

Antibiotic sensitivity pattern of TEM-116 betalactamase producing $P$. aeruginosa isolates were determined by modified Kirby-Bauer method [12]. A $0.5 \mathrm{McF}$ arland dilution of refreshed bacterial isolate was inoculated on Mueller Hinton agar (MHA). Antibiotic discs (Oxoid, UK) including amoxycillin/clavulanic acid (AMC), aztreonam (ATM), ceftazidime (CAZ), cefepime (FEP), imipenem (IPM) ceftriaxone (CRO), amikacin (AK), doxycycline (DO), gentamicin (CN), ciprofloxacin (CIP), norfloxacin (NOR), levofloxacin (LEV), sulphamethoxazole/trimethoprim (SXT), sulzone (SCF) and chloramphenicol (C) were placed on MHA plates and then incubated overnight. After incubation, zones of inhibition were measured and interpreted in accordance with Clinical Laboratory Standard Institute (CLSI) guidelines [13].

\section{E-test}

Quantitative minimum inhibitory concentrations (MICs) of the selected antibiotics (including ciprofloxacin, ceftriaxone, gentamicin and amikacin) against TEM 116 beta-lacatamseproducing $P$. aeruginosa were evaluated by $\mathrm{E}$ test in accordance with manufacturer's instructions (AB Biodisk, Solna, Sweden).

\section{RESULTS}

Among the $102 P$. aeruginosa isolates, the amplified product of $972 \mathrm{bp}$ corresponding to TEM gene size was found in 23 isolates (22.5\%) (Figure 1).

TEM amplified gene product was processed for sequencing. When nucleotide sequence was translated into amino acids, it showed $100 \%$ amino acid sequence homology with TEM 116. In chromatogram the nucleotides at position c. $250 \mathrm{G}>\mathrm{A}$ and c.551C $>\mathrm{T}$, refer to the substituted nucleotides and p.Val84lle and p.Ala184Val refer to the amino acids substitutions at these two positions in comparison to the original TEM 1 gene sequence (Figure 2). 


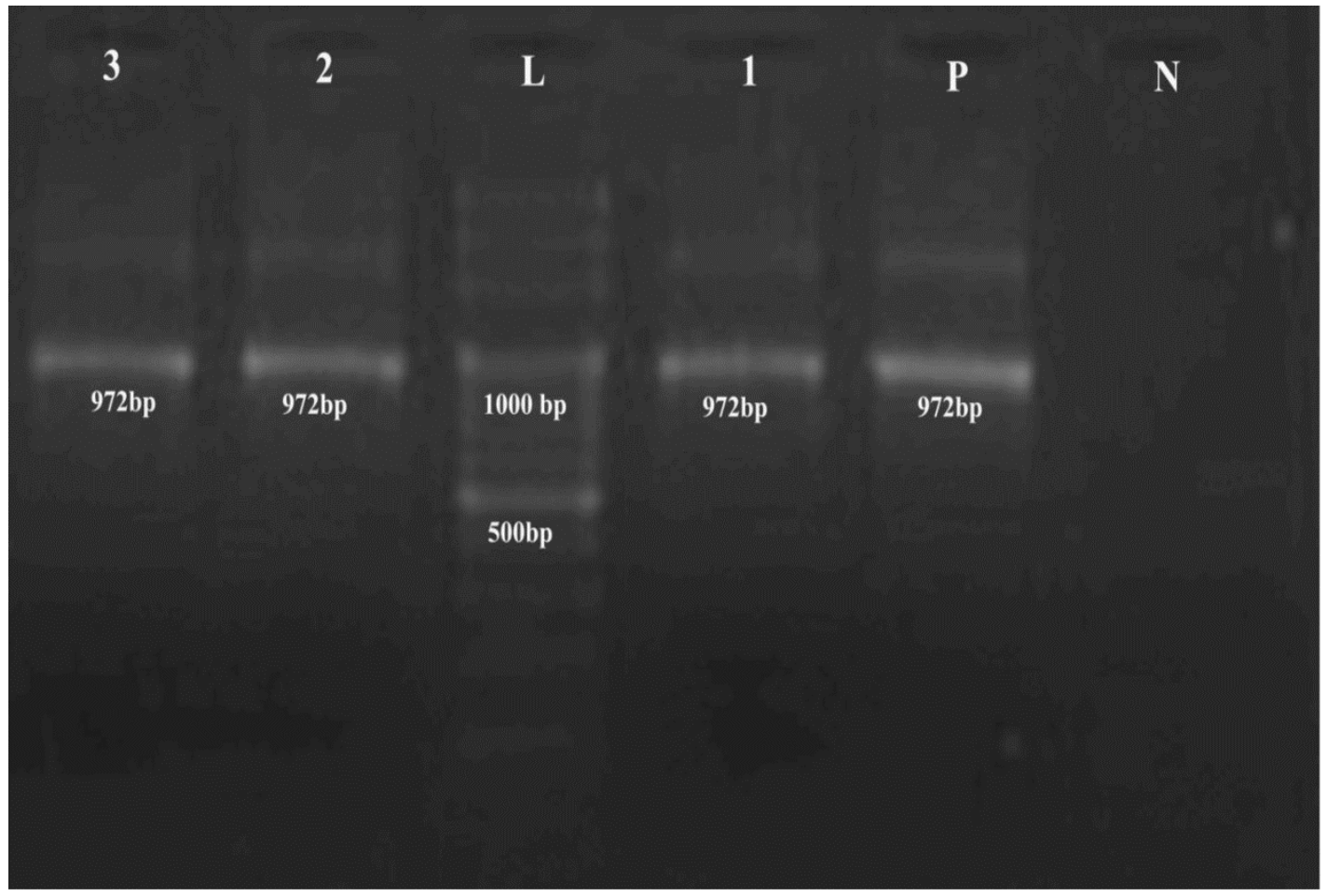

Figure 1: Detection of TEM beta-lacatamase gene in $P$. aeruginosa: TEM gene (972bp) was specifically amplified and resolved on $1.8 \%$ agarose gel. 1, 2 and 3 in the gel indicated TEM gene amplification. L: Lader, P: Positive control, N: Negative control
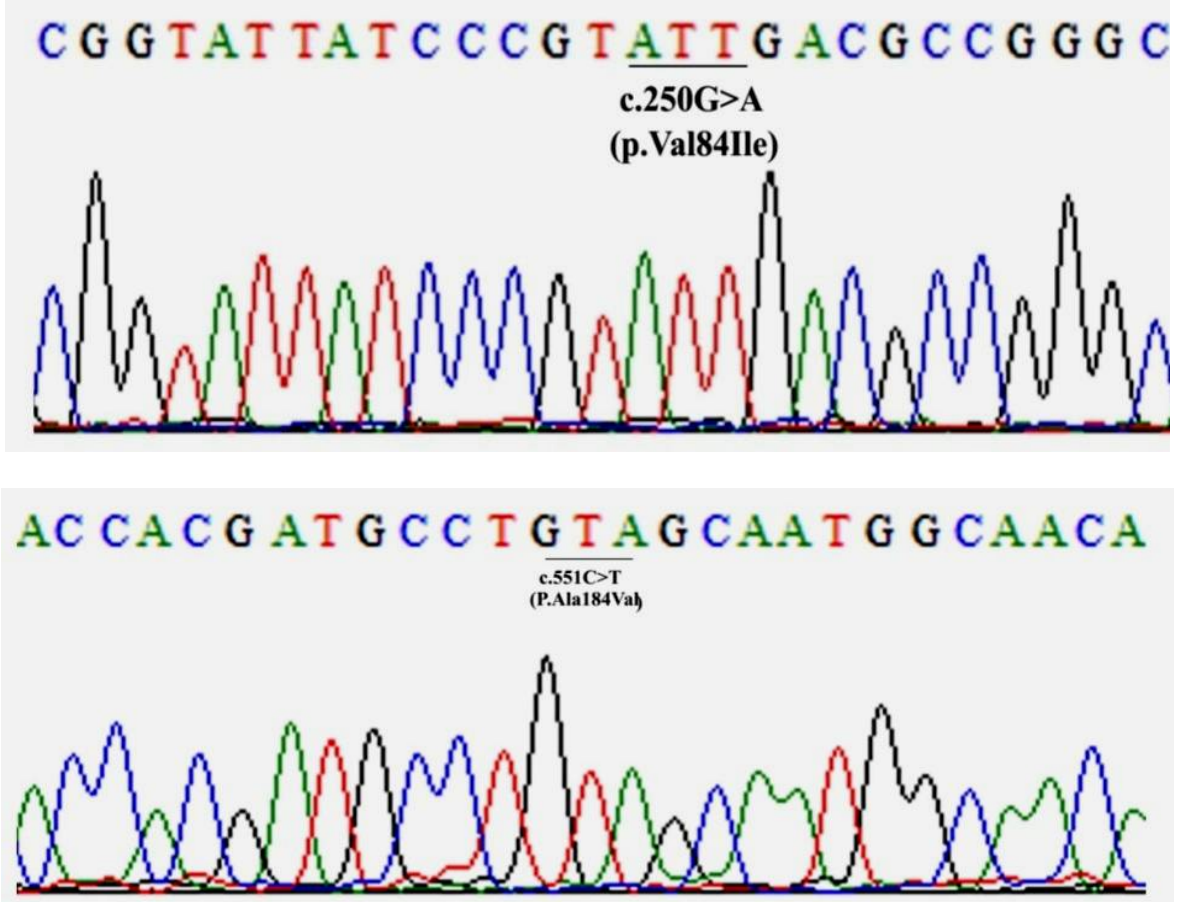

Figure 2: Chromatogram of the sequenced data showing mutation in nucleotides at positions 250 and 551 for the corresponding amino acids Ile and Val in TEM 116

BLAST analysis of the translated amino acids sequence with TEM 1, showed two mutations that include replacement of valine by isoleucine at position 84, and replacement of alanine by valine at position 184 (Table 1). The two mutations at positions 84 and 184 confirmed the presence of TEM-116 when used online tool (http://www.laced.uni-stuttgart.de). 
Table 1: Amino acid substitutions of TEM-116 beta-lacatamase-producing $P$. aeruginosa

\begin{tabular}{llc}
\hline $\begin{array}{l}\text { Beta } \\
\text { lactamase }\end{array}$ & \multicolumn{2}{l}{$\begin{array}{l}\text { Residue (triplet code) at } \\
\text { amino acid: }\end{array}$} \\
\cline { 2 - 3 } & $\mathbf{8 4}$ & $\mathbf{1 8 4}$ \\
\hline TEM-1 & Val (GTT) & Ala (GCA) \\
TEM-116 & lle (ATT) & Val (GTA) \\
\hline
\end{tabular}

After analysis of sequence homology, the TEM116 beta-lactamase producing isolates were processed for antibiotic susceptibility pattern. The TEM-116 isolates showed $100 \%$ resistance $(\mathrm{n}=7)$ to sulphamethoxazole/trimethoprim, amoxycillin/clavulanic acid and doxycycline. However they showed increased sensitivity to levofloxacin, norfloxacin and amikacin. One isolate, PA11 showed resistance to all the antibiotics used in the study (Table 2).

MICs were determined to assess the quantitative inhibitory concentration of commonly used antibiotics against TEM producing $P$. aeruginosa. It was found that MIC of ceftriaxone was $>512$ $\mu \mathrm{g} / \mathrm{ml}$ against three isolates (PA5, PA9 and PA11) while PA11 isolate was found to be the most resistant among all TEM-116 producing isolates (Table 3).

\section{DISCUSSION}

Resistance to beta-lactam antibiotics in communities and hospitals has created a major health problem leading to increased mortality, morbidity and high health care expenses.
Production of extended spectrum betalactamases (ESBLs) in bacteria is the principle mechanism of resistance against beta-lactam antibiotics. Among ESBLs, TEM beta-lactamase family has variable diversity, prevalence and global distribution [11]. In TEM family, TEM-116 was first reported among Enterobacteriaceae in Korea [14] and in P. fluorescens [15]. One study has documented co-production of TEM-116 and $\mathrm{SHV}-2 \mathrm{a}$ in $P$. aeruginosa isolates in France [16].In the present study, TEM-116 showed two point mutations which cause amino acid substitution from valine to isoleucine at position 84 and alanine to valine at position 184. Similar mutations in TEM 116 were also reported in $P$. fluorescens [15].

When antibiotic susceptibility pattern was checked, it was found that TEM 116-producing $P$. aeruginosa isolates exhibited maximum resistance to sulphamethoxazole/trimethoprim, amoxycillin/clavulanic acid and doxycycline. In several studies, ESBLs and TEM 116 isolates were highly resistant to commonly available antibiotics [16-18]. These reports are in line with our findings. Moreover TEM-116 producers in the current study exhibited sensitivities to levofloxacin, norfloxacin and amikacin, which indicate effective bacteriostatic activity against the TEM-116 isolates. When bacteriostatic activities of selected antibiotics including ciprofloxacin, ceftriaxone, gentamicin and amikacin were checked, they showed similar variable activities as reported earlier [17].

Table 2: Antibiotic susceptibility pattern of TEM 116 beta-lacatamase-producing $P$. aeruginosa

\begin{tabular}{|c|c|c|c|c|c|c|c|c|c|c|c|c|c|c|c|}
\hline $\begin{array}{l}\text { Isolat } \\
\text { es }\end{array}$ & LEV & IPM & CRO & CAZ & C & $\begin{array}{l}\mathbf{C} \\
\mathbf{N}\end{array}$ & CIP & $\begin{array}{c}\text { SX } \\
T\end{array}$ & $\begin{array}{c}\text { SC } \\
F\end{array}$ & AMC & NOR & AK & DO & $\begin{array}{c}\text { FE } \\
P\end{array}$ & $\overline{\text { ATM }}$ \\
\hline PA1 & $\mathrm{R}$ & $\mathrm{R}$ & $\mathrm{S}$ & $\mathrm{S}$ & $\mathrm{R}$ & $\mathrm{R}$ & $\mathrm{R}$ & $\mathrm{R}$ & $\mathrm{R}$ & $\mathrm{R}$ & $\mathrm{R}$ & $\mathrm{R}$ & $\mathrm{R}$ & $\mathrm{R}$ & $\mathrm{R}$ \\
\hline PA2 & $\mathrm{R}$ & $\mathrm{R}$ & $\mathrm{R}$ & $\mathrm{R}$ & $S$ & $\mathrm{R}$ & $\mathrm{R}$ & $\mathrm{R}$ & $\mathrm{R}$ & $\mathrm{R}$ & $\mathrm{R}$ & $\mathrm{R}$ & $\mathrm{R}$ & $\mathrm{R}$ & $\mathrm{R}$ \\
\hline PA3 & $S$ & $S$ & $S$ & $S$ & $\mathrm{R}$ & $S$ & $S$ & $\mathrm{R}$ & $S$ & $\mathrm{R}$ & $S$ & $S$ & $\mathrm{R}$ & $S$ & $S$ \\
\hline PA5 & $\mathrm{R}$ & $S$ & $\mathrm{R}$ & $\mathrm{R}$ & $\mathrm{R}$ & $\mathrm{R}$ & $\mathrm{R}$ & $\mathrm{R}$ & $S$ & $\mathrm{R}$ & $\mathrm{R}$ & $S$ & $\mathrm{R}$ & $\mathrm{R}$ & $\mathrm{R}$ \\
\hline PA9 & $S$ & $\mathrm{R}$ & $\mathrm{R}$ & $\mathrm{R}$ & $\mathrm{R}$ & $S$ & $S$ & $\mathrm{R}$ & 1 & $\mathrm{R}$ & $S$ & $\mathrm{~S}$ & $\mathrm{R}$ & $\mathrm{R}$ & $\mathrm{R}$ \\
\hline PA11 & $\mathrm{R}$ & $\mathrm{R}$ & $\mathrm{R}$ & $\mathrm{R}$ & $\mathrm{R}$ & $\mathrm{R}$ & $\mathrm{R}$ & $\mathrm{R}$ & $\mathrm{R}$ & $\mathrm{R}$ & $\mathrm{R}$ & $\mathrm{R}$ & $\mathrm{R}$ & $\mathrm{R}$ & $\mathrm{R}$ \\
\hline PA20 & $S$ & 1 & $R$ & $\mathrm{R}$ & $\mathrm{R}$ & $\mathrm{R}$ & $\mathrm{R}$ & $R$ & $\mathrm{R}$ & $R$ & $S$ & $\mathrm{R}$ & $\mathrm{R}$ & $R$ & $\mathrm{R}$ \\
\hline
\end{tabular}

$R$; resistance, l; intermediate, S; sensitive

Table 3: MIC of selected antimicrobial agents against TEM 116 producing Pseudomonas aeruginosa isolates

\begin{tabular}{lcccc}
\hline Isolate & \multicolumn{4}{c}{ Antibiotic MIC $(\boldsymbol{\mu g} \mathbf{g} \mathbf{m l})$} \\
\cline { 2 - 5 } & Ciprofloxacin & Ceftriaxone & Gentamicin & Amikacin \\
\hline PA1 & $\leq 8$ & 16 & 128 & 64 \\
PA2 & 32 & 64 & 128 & 128 \\
PA3 & 1 & 16 & $\leq 8$ & $\leq 8$ \\
PA5 & 128 & $>512$ & $>512$ & 256 \\
PA9 & $>512$ & $\leq 8$ & $\leq 8$ \\
PA11 & 32 & $>512$ & $>512$ & $>512$ \\
PA20 & $>512$ & 32 & 128 & 16 \\
\hline
\end{tabular}


Among these isolates (PA11) showed resistance to all the antibiotics used in the study. The possible reason might be the presence of full spectrum of beta lactamases and other virulence factors in this isolate (PA11).

\section{CONCLUSION}

In the present study, increased antibiotic resistance was reported in the TEM-116 $P$. aeruginosa isolates from Pakistan. These findings are considered beneficial in understanding the mechanism(s) involved in development of antibiotic resistance in $P$. aeruginosa.

\section{DECLARATIONS}

\section{Conflict of Interest}

No conflict of interest associated with this work.

\section{Contribution of Authors}

The authors declare that this work was done by the authors named in this article and all liabilities pertaining to claims relating to the content of this article will be borne by them.

\section{Open Access}

This is an Open Access article that uses a funding model which does not charge readers or their institutions for access and distributed under the terms of the Creative Commons Attribution License (http://creativecommons.org/licenses/by 14.0) and the Budapest Open Access Initiative (http://www.budapestopenaccessinitiative.org/rea d), which permit unrestricted use, distribution, and reproduction in any medium, provided the original work is properly credited.

\section{REFERENCES}

1. Farshadzadeh Z, Khosravi AD, Alavi SM, Parhizgari $N$, Hoveizavi H.Spread of extended-spectrum $\beta$-lactamase genes of bla OXA-10, bla PER-1 and bla CTX-M in Pseudomonas aeruginosa strains isolated from burn patients. Burns 2014; 40: 1575-1580

2. Bonomo RA, Szabo D. Mechanisms of multidrug resistance in Acinetobacter species and Pseudomonas aeruginosa. J Clin Infect Dis 2006; 43(2): 49-56.

3. Rossolini GM, Mantengoli E. Treatment and control of severe infections caused by multiresistant Pseudomonas aeruginosa. J Clin Microbiol Infect 2005; 11(4): 17-32.

4. Farida A, Mir A. Susceptibility pattern of Pseudomonas aeruginosa against various antibiotics. Afr JMicrobiol Res 2010; 4: 1005-1012.
5. Pagani L, Mantengoli E, Migliavacca R, Nucleo E, Pollini $S$, Spalla $M$, Daturi R, Romero E, Rossolini GM. Multifocal detection of multidrug-resistant Pseudomonas aeruginosa producing the PER-1 extended spectrum_ $\beta$ lactamase in northern Italy. J Clin Microbiol 2004; 39: 1865-1870.

6. Arlet G, Brami G, Decre D, Flippo JL, Gaillot O, Lagrange $P H$, Philippon A.Molecular characterisation by $P C R$-restriction fragmentlength polymorphism of TEM $\beta$ lactamases. FEMS Microbiol Lett 1995; 134: 203-208.

7. Lowbury EJL, Kidson A, Lilly HA, Ayliffe GA, Jones RJ. Sensitivity of Pseudomonas aeruginosa to antibiotics: emergence ofstrains highly resistant to carbenicillin. Lancet 1969; 2: 448-452.

8. Shakibaie MR, Shahcheraghi F, Hashemi A, Saeed AN. Detection of TEM, HSV and PER type extended spectrum beta- lactamases genes among clinical strains of Pseudomonas aeruginosa isolated from burnt patients at Shafa-hospital, Kerman, Iran. Iranian J Basic Med Sci 2008; 11: 104-111.

9. Livermore DM. $\beta$-Lactamases in laboratory and clinical resistance. Clin. Microbiol. Rev1995; 8: 557-584.

10. Ullah W, Qasim M, Rahman H, Bari F, Khan S, Rehman Z, Khan Z, Dworeck T, Muhammad N.. Multi drug resistant Pseudomonas aeruginosa: Pathogen burden and associated antibiogram in a tertiary care hospital of Pakistan. Microb Path 2016: 97: 209-212

11. Sutcliffe JG. Nucleotide sequence of the ampicillin resistance gene of Escherichia coli plasmid pBR322. Proc Natl Acad Sci USA 1978; 75(8): 3737-3741.

12. Kirby WM, Yoshihara GM, Sundsted KS, Warren JH. Clinical usefulness of a single disc method for antibiotic sensitivity testing. Antibiotics Annual 1956; 1: 892-897.

13. Clinical Laboratory Standards Institute. Performance standards for antimicrobial susceptibility testing; 16th informational supplement. U.S.A: CLSI M100-S16, Clinical and Laboratory Standards InstituteWayne, PA. 2007.

14. Jeong SH, Bae IK, Lee JH, Sohn SG, Kang GH, Jeon GJ, Kim YH, Jeong BC, Lee SH. Molecular characterization of extended-spectrum beta-lactamases produced by clinical isolates of Klebsiella pneumoniae and Escherichia coli from a Korean nationwide survey. J Clin Microbiol 2004; 42: 2902-2906.

15. Maravic A, Skocibusic M, Samanic I, Puizina J.Antibiotic susceptibility profiles and first report of TEM extendedspectrum $\beta$-lactamase in Pseudomonas fluorescens from coastal waters of the Kaštela Bay, Croatia. World J Microbiol Biotechnol 2012; 28(5): 2039-2045.

16. David M, Lemeland JF, Boyer S. Emergence of extendedspectrum beta-lactamases in Pseudomonas aeruginosa: about 24 cases at Rouen University Hospital. Pathol Biol (Paris) 2008; 56(7-8): 429-434.

17. Ndugulile $F$, Jureen $R$, Harthug $S$, Urassa W, Langeland $N$. Extended spectrum beta-lactamases among Gramnegativebacteria of nosocomial origin from an intensive careunit of a tertiary health facility in Tanzania. BMC Infect Dis 2005; 5: 86.

Trop J Pharm Res, January 2017; 16(1): 153 
Ullah et al

18. $H u G Z$, Chen $H Y$, Si HB, Deng $L X$, Wei $Z Y$, Yuan $L$, Kuang $X H$. Phenotypic and molecularcharacterization of TEM-116 extended-spectrum beta-lactamaseproduced by a Shigella flexneri clinicalisolate from chickens. FEMS Microbiol Lett 2008; 279(2): 162-166. 